\title{
Humidification in Intensive Care: Are We There Yet?
}

It is now more than 60 years since the polio epidemic in Denmark in 1952 that led, at least partly, to the development of artificial ventilation. ${ }^{1}$ In the report of that epidemic, Lassen stated that "A good humidifier is essential: otherwise incrustation of secretions may occur." Subsequent to the polio epidemic, a heated humidifier was described by Marshall and Spalding in $1953,{ }^{2}$ and Drägerwerk AG \& Co filed a patent for a heat-and-moisture exchanger (HME) in $1954 .{ }^{3}$ It is sobering to reflect now that even after $60 \mathrm{y}, 2$ topics, (1) what makes a good humidifier and (2) which of the 2 types of device, heated humidifier or HME, is better for the patient, are still being debated. To add to the debate, there is the more recent

\section{See the Original Study on Page 637}

development of an active HME, where the performance of an HME is augmented by the addition of water, which is then heated and evaporated. ${ }^{4}$ An additional topic that follows from topic (1) is how best to test these various devices to obtain appropriate information on humidification performance to make an informed decision.

In this edition of Respiratory CARE, Lellouche et $\mathrm{al}^{5}$ add to this debate by comparing the performances of 2 HMEs and an active HME at different ambient temperatures and minute ventilations $\left(\dot{\mathrm{V}}_{\mathrm{E}}\right)$. The authors conclude that variations in ambient temperature and $\dot{\mathrm{V}}_{\mathrm{E}}$ have negligible effects on the humidification performance of HMEs and active HMEs. This is an important addition to the evidence available on the use of these devices. However, there are some important issues arising from this work.

\section{International Standards}

International standards are available for use when testing the performance of many different types of medical

\footnotetext{
Dr Wilkes helped carry out testing for manufacturers of heat-and-moisture exchangers on a commercial basis until 2012 through Cardiff University (no direct personal financial gain). He has been contracted as a consultant on medical devices to CEN, the European Standards Committee.
}

Correspondence: Antony R Wilkes PhD. E-mail: t.wilkes@talk21.com.

DOI: $10.4187 /$ respcare. 03232 devices. The use of standards helps ensure that data obtained on the performance of devices by different groups can be usefully compared. This then helps users and purchasers make an informed choice when choosing between different devices.

The current international standard for HMEs (ISO 93601:2000) includes tests for the effect of $\dot{V}_{E}$ on humidification performance by specifying 4 different test conditions, but not the effect of ambient temperature. ${ }^{6}$ The current international standard for heated humidifiers (ISO 8185: 2007) includes the effect of variations in continuous gas flow, but not $\dot{\mathrm{V}}_{\mathrm{E}}$ (in terms of tidal volume $\left[\mathrm{V}_{\mathrm{T}}\right]$ and breathing frequency) or ambient temperature. ${ }^{7}$ Because the test methods specified for HMEs and heated humidifiers are different, it is difficult to make a comparison between the humidification performances of these 2 types of devices.

\section{Effect of $\dot{V}_{E}$ on Humidification Performance of HMEs}

$\dot{\mathrm{V}}_{\mathrm{E}}$ is the product of $\mathrm{V}_{\mathrm{T}}$ and frequency (f), such that $\dot{\mathrm{V}}_{\mathrm{E}}$ $(\mathrm{L} / \mathrm{min})=\mathrm{V}_{\mathrm{T}}(\mathrm{L}) \times \mathrm{f}$ (breaths $\left./ \mathrm{min}\right)$. Therefore, to alter $\dot{\mathrm{V}}_{\mathrm{E}}$, the $\mathrm{V}_{\mathrm{T}}$, frequency, or both can be varied.

Lellouche et $\mathrm{al}^{5}$ chose 2 values of $\dot{V}_{\mathrm{E}}$ (Table 1). They concluded that variation in $\dot{V}_{\mathrm{E}}$ had negligible influence on the humidification performance of HMEs. This is impressive, as $\dot{V}_{\mathrm{E}}$ was doubled from 10 to $20 \mathrm{~L} / \mathrm{min}$ (Table 1). However, as $\dot{\mathrm{V}}_{\mathrm{E}}$ is composed of 2 components (as shown in the above equation), it is perhaps worth investigating this further. The increase in $\mathrm{V}_{\mathrm{T}}$ was modest, an increase of $0.15 \mathrm{~L}$ from 0.50 to $0.65 \mathrm{~L}(30 \%)$. The increase in frequency from 20 to 30 breaths/min was greater (50\%), but which of the 2 components of $\dot{V}_{\mathrm{E}}, \mathrm{V}_{\mathrm{T}}$ or frequency, is likely to have a greater effect on humidification performance?

\section{Effects of $V_{T}$ and Frequency on Humidification Performance}

The first edition of the international standard for HMEs was published in $1992 .{ }^{8}$ This included a test method for determining the humidification performance at different combinations of $\mathrm{V}_{\mathrm{T}}$ and frequency (the inspiratory-expiratory ratio was also varied for some test conditions, but is not included in this discussion). For HMEs intended for 
Table 1. Test Conditions Used by Lellouche et $\mathrm{al}^{5}$

\begin{tabular}{lccc}
\hline \hline $\begin{array}{c}\text { Test } \\
\text { Condition }\end{array}$ & $\begin{array}{c}\text { Tidal Volume } \\
(\mathrm{L})\end{array}$ & $\begin{array}{c}\text { Frequency } \\
\text { (breaths/min) }\end{array}$ & $\begin{array}{c}\text { Minute Ventilation } \\
(\mathrm{L} / \mathrm{min})\end{array}$ \\
\hline 1 & 0.50 & 20 & 10 \\
2 & 0.65 & 30 & 20 \\
\hline
\end{tabular}

Table 2. Test Conditions for Heat-and-Moisture Exchangers Intended for Use With Adults From ISO 9360:1992 ${ }^{8}$ Used by Eckerbom and Lindholm ${ }^{9}$ and Branson and Davis ${ }^{10}$

\begin{tabular}{lccc}
\hline \hline $\begin{array}{c}\text { Test } \\
\text { Condition }\end{array}$ & $\begin{array}{c}\text { Tidal Volume } \\
\text { (L) }\end{array}$ & $\begin{array}{c}\text { Frequency } \\
\text { (breaths/min) }\end{array}$ & $\begin{array}{c}\text { Minute Ventilation } \\
\text { (L/min) }\end{array}$ \\
\hline 1 & 1.0 & 20 & 20 \\
2 & 1.0 & 10 & 10 \\
3 & 0.5 & 20 & 10 \\
\hline
\end{tabular}

use with adults, the test conditions comprised the $\mathrm{V}_{\mathrm{T}}$ values and frequencies shown in Table 2.

Thus, comparing results from test conditions 1 and 2 indicates an effect of changing the frequency, whereas comparing results from test conditions 2 and 3 indicates an effect of changing the $\mathrm{V}_{\mathrm{T}}$, provided the effect of changing the frequency was small.

Two studies compared the humidification performance of HMEs using test methods and conditions based on the ISO 9360:1992 standard. ${ }^{9,10}$ In both studies, there was a more marked effect on the humidification performance upon changing $\mathrm{V}_{\mathrm{T}}$ from 0.5 to $1.0 \mathrm{~L}$ (equivalent to a $100 \%$ increase) compared with changing the frequency from 10 to $20 / \mathrm{min}$ (again, equivalent to a $100 \%$ increase), suggesting that $\mathrm{V}_{\mathrm{T}}$ has the primary effect on humidification performance, whereas the frequency effect is secondary. The difference in humidification performance under the different test conditions was small for those devices that performed well, but the effect of increasing $\mathrm{V}_{\mathrm{T}}$ to $1.0 \mathrm{~L}$ for some devices that performed more poorly at $\mathrm{V}_{\mathrm{T}} 0.5 \mathrm{~L}$ was marked.

The more pronounced effect of $\mathrm{V}_{\mathrm{T}}$ on humidification performance compared to frequency also makes sense from a theoretical point of view. An HME is designed to retain moisture during expiration and release the retained moisture during inspiration to humidify the inspired gas. The expired gas produced by the test rig used by Lellouche et $\mathrm{al}^{5}$ was set at a temperature of $33^{\circ} \mathrm{C}$ with an absolute humidity level of $35 \mathrm{mg} / \mathrm{L}$. Therefore, an expired $\mathrm{V}_{\mathrm{T}}$ of $0.5 \mathrm{~L}$ would contain $17.5 \mathrm{mg}$ of water vapor, and the HME would be designed to retain a large proportion of this water (eg, to return $30 \mathrm{mg} / \mathrm{L}$ would require an efficiency of $86 \%$ ). Doubling the $\mathrm{V}_{\mathrm{T}}$ would double the mass of water vapor (to $35 \mathrm{mg}$ ), and the capacity of the HME to retain this additional mass of water vapor may be limited, particularly for some devices. In contrast, the effect of in-
Table 3. Test Conditions for Heat-and-Moisture Exchangers From ISO 9360-1:20006

\begin{tabular}{lccc}
\hline \hline $\begin{array}{c}\text { Test } \\
\text { Condition }\end{array}$ & $\begin{array}{c}\text { Tidal Volume } \\
(\mathrm{L})\end{array}$ & $\begin{array}{c}\text { Frequency } \\
\text { (breaths/min) }\end{array}$ & $\begin{array}{c}\text { Minute Ventilation } \\
(\mathrm{L} / \mathrm{min})\end{array}$ \\
\hline 1 & 1.0 & 10 & 10 \\
2 & 0.75 & 12 & 9 \\
3 & 0.50 & 15 & 7.5 \\
4 & 0.25 & 20 & 5 \\
\hline
\end{tabular}

creasing the frequency is only to reduce the time that the HME has available to retain the moisture; it does not affect its capacity to do so.

The current international standard for $\mathrm{HMEs}^{6}$ still requires a test to be carried out using a test condition with $\mathrm{V}_{\mathrm{T}} 1.0 \mathrm{~L}$ (Table 3). This is much greater than the $\mathrm{V}_{\mathrm{T}}$ used as a maximum by Lellouche et $\mathrm{al}^{5}(0.65 \mathrm{~L})$. Hence, the effect of increasing $\mathrm{V}_{\mathrm{T}}$ on performance may be missed if one instead concentrates on the effect of the composite term $\dot{\mathrm{V}}_{\mathrm{E}}$ on humidification performance.

\section{Effect of Ventilation Strategy on Humidification Performance and Use of HMEs}

Lellouche et $\mathrm{al}^{5}$ used $2 \mathrm{~V}_{\mathrm{T}}$ values in their study and concluded that $\dot{\mathrm{V}}_{\mathrm{E}}$ had negligible influence on humidification performance. This contrasted with the conclusions reached in the 2 studies by Martin et al in $1992^{11}$ and $1995^{12}$ cited by Lellouche et al, in which the adverse effect of increasing $\dot{\mathrm{V}}_{\mathrm{E}}$ above $10 \mathrm{~L} / \mathrm{min}$ on humidification performance was first described. However, the mean \pm SD $\mathrm{V}_{\mathrm{T}}$ values used to ventilate the subjects in the 2 studies by Martin et al were $0.785 \pm 0.132 \mathrm{~L}$ and $0.694 \pm 0.143 \mathrm{~L}$, respectively; both means are therefore above the greater of the $2 \mathrm{~V}_{\mathrm{T}}$ values used by Lellouche et $\mathrm{al}^{5}(0.65 \mathrm{~L})$. The effect noted by Martin et al may have been missed by Lellouche et al not only because of the different devices used by the authors, but also because of the difference in $\mathrm{V}_{\mathrm{T}}$ values.

It is also interesting to note that the mean $\dot{V}_{\mathrm{E}}$ during the clinical study carried out by Lellouche et $\mathrm{al}^{5}$ was $12.4 \mathrm{~L} /$ $\min$. In the 2 studies by Martin et al ${ }^{11,12}$ cited by Lellouche et al, the mean $\pm \mathrm{SD} \dot{\mathrm{V}}_{\mathrm{E}}$ values were $13.1 \pm 1.7 \mathrm{~L} / \mathrm{min}$ and $11.9 \pm 1.2 \mathrm{~L} / \mathrm{min}$, respectively, similar to that in the clinical study by Lellouche et al. However, comparing these values and the $\dot{\mathrm{V}}_{\mathrm{E}}$ values specified in the current edition of ISO 9360-1:2000 (Table 3) to the $\dot{V}_{\mathrm{E}}$ values of 10 and $20 \mathrm{~L} / \mathrm{min}$ used in the bench study by Lellouche et al suggests that a test condition using $\dot{\mathrm{V}}_{\mathrm{E}} 20 \mathrm{~L} / \mathrm{min}$ is rather excessive (although in keeping with the maximum $\dot{\mathrm{V}}_{\mathrm{E}}$ specified in the first edition of ISO 9360:1992 [Table 2] ${ }^{8}$ and from the studies already mentioned ${ }^{9,10}$ ).

Martin et $\mathrm{al}^{11}$ also stated a mean $\pm \mathrm{SD}$ for the ventilation strategy of $12.4 \pm 3 \mathrm{~mL} / \mathrm{kg}$ (range $8.1-16.4 \mathrm{~mL} / \mathrm{kg}$ ) in 
the study from 1992. This is larger than would be considered appropriate today, more than 20 years later, when guidance has been published to start artificial ventilation at $8 \mathrm{~mL} / \mathrm{kg}$ and to reduce ventilation to $6 \mathrm{~mL} / \mathrm{kg}$ (or to a minimum of $4 \mathrm{~mL} / \mathrm{kg}$ ) when possible. ${ }^{13}$

The guidance on ventilation strategy is based on predicted body weight. ${ }^{13}$ For example, for males, the predicted body weight $(\mathrm{kg})$ is $50+2.3 \times$ (height [inches] 60). For a male who is $6 \mathrm{ft}$ tall (72 in), the predicted body weight is $50+2.3 \times(72-60)=77.6 \mathrm{~kg}$. Following the guidance for an $80-\mathrm{kg}$ male, the $\mathrm{V}_{\mathrm{T}}$ would range from 320 to $640 \mathrm{~mL}$, which is considerably less than the maximum $\mathrm{V}_{\mathrm{T}}$ of $1.0 \mathrm{~L}$ specified in the standard. However, manufacturers are obliged to declare a range of $\mathrm{V}_{\mathrm{T}}$ values over which their HMEs can be used, and it is appropriate that the performance of the HME should be tested at the limits of that range.

In general, from the earlier discussion, in order to obtain the best humidification performance from an HME while maintaining the same $\dot{\mathrm{V}}_{\mathrm{E}}$, it is preferable to reduce the $\mathrm{V}_{\mathrm{T}}$ and to increase the frequency where possible. Fortunately, this also is in line with the guidance to help protect the patient's lungs. ${ }^{13}$

Good humidification is one criterion to consider when choosing an HME. Other criteria are dead space (from the internal volume) and the work of breathing (from the resistance to gas flow).

Unfortunately, following the guidance to reduce the $\mathrm{V}_{\mathrm{T}}$ causes the effect of the HME's internal volume on rebreathing to be more pronounced. Lellouche et $\mathrm{al}^{5}$ included 2 HMEs in their study, the Hygrobac and the Hygrobac S (Tyco Healthcare, Raleigh, North Carolina), with 2 different internal volumes, 95 and $45 \mathrm{~mL}$, respectively. Given the small difference in humidification performance between these 2 devices, the Hygrobac $S$, with its smaller internal volume, is probably the preferred option if $\mathrm{V}_{\mathrm{T}}$ is being reduced. However, this advantage is slightly counterbalanced by the fact that its resistance to gas flow is $\sim 10 \%$ greater (2.3 compared with $2.1 \mathrm{~cm} \mathrm{H}_{2} \mathrm{O} / \mathrm{L} / \mathrm{min}$ ).

\section{What Is a Good Humidifier?}

Returning to the question of humidification performance: what level of humidification performance would constitute a good humidifier? On the basis of a recent review of the literature, I suggested that $30 \mathrm{mg} / \mathrm{L}$, as originally proposed by Chamney in $1969,{ }^{14}$ be considered an appropriate minimum level of humidification. ${ }^{15}$ Interestingly, this was the level set as the minimum level in the first edition of the international standard for heated humidifiers, ${ }^{16}$ but this was subsequently increased to $33 \mathrm{mg} / \mathrm{L}^{7}$ (the current standard for HMEs [ISO 9360-1:2000] does not specify a minimum level of performance ${ }^{8}$ ). However, this is above the level that can normally be delivered by HMEs (confirmed by Lellouche et $\mathrm{al}^{5}$ ). Given the level of use of HMEs over the past 20 years or more to provide humidification during long-term mechanical ventilation in ICUs for a broad range of patient groups and the number of studies that have been carried out attesting to their acceptability, this seems rather high as a minimum level. As Lellouche et $\mathrm{al}^{5}$ pointed out, there is "no clinical demonstration of the superiority of delivering 40 versus $30 \mathrm{mg} \mathrm{H}_{2} \mathrm{O} / \mathrm{L}$," and this is also true for 33 versus $30 \mathrm{mg} / \mathrm{L}$. The optimum level of humidification may, of course, be $>30 \mathrm{mg} / \mathrm{L}$.

\section{Effect of Expired Temperature and Humidity on Humidification Performance}

Lellouche et $\mathrm{al}^{5}$ set the temperature and absolute humidity of the air expired from their test rig at $33^{\circ} \mathrm{C}$ and $35 \mathrm{mg} / \mathrm{L}$, respectively. As stated above, to return $30 \mathrm{mg} / \mathrm{L}$ under these test conditions would require the HME to be $86 \%$ efficient in retaining and releasing water vapor. The test condition for the expired gas specified in the first edition of the international standard for $\mathrm{HMEs}^{8}$ was an expired air temperature of $34^{\circ} \mathrm{C}$ fully saturated with water vapor, equivalent to a moisture content of $37.6 \mathrm{mg} / \mathrm{L}$. To return $30 \mathrm{mg} / \mathrm{L}$ under these test conditions is then less of a challenge for the HME, as the required efficiency is now only $80 \%$. In contrast, if the HME is still $86 \%$ efficient, then it would return $32 \mathrm{mg} / \mathrm{L}$. The current edition of the standard only specifies the temperature of the water bath in the test rig $\left(37^{\circ} \mathrm{C}\right)$; the expired temperature is allowed to vary depending on the performance of the HME. However, if there was no cooling from the water bath to the mouth of the test rig, then expired air would contain $44 \mathrm{mg} / \mathrm{L}$ at $37^{\circ} \mathrm{C}$, with obvious consequences for determining the humidification performance of HMEs (however, it should be noted that the current edition of the standard determines humidification performance in terms of net moisture loss from the test rig and not moisture returned to the patient, thus making comparisons between different sets of data even more difficult). In contrast, early work in this area, for example that of Branson ${ }^{17}$ (carried out prior to publication of the first edition of the standard for HMEs), used an expired temperature of $32^{\circ} \mathrm{C}$. Fully saturated air at this temperature has an absolute humidity level of $34 \mathrm{mg} / \mathrm{L}$. Hence, there is less humidity available for the HME to return. Clearly, it is important that if comparisons are to be made, the same test protocol (including temperature and humidity) should be used.

\section{Effect of Ambient Temperature on Humidification Performance}

The negligible effect of ambient temperature on humidification performance of HMEs found by Lellouche et $\mathrm{al}^{5}$ is welcome news for those working in areas of the world 


\section{Humidification in Intensive Care: Are We There Yet?}

where the ambient temperature is not maintained close to the ambient temperatures specified in the standard $\left(23 \pm 2^{\circ} \mathrm{C}\right)$ when carrying out tests, and this indicates that HMEs can still be used to provide adequate humidification in these different climates. As changes in ambient temperature have only a negligible effect on the humidification performance of HMEs, it is probably immaterial that such a test is not included in the international standard for HMEs. However, previous work by the authors ${ }^{18}$ demonstrating an effect of changes in ambient temperature on the performance of heated humidifiers suggests that a test to determine this effect should be developed for the international standard.

\section{Conclusions}

The availability of independent evidence of the performance of HMEs is crucial to allow an informed choice to be made between the many different models available on the market, and Lellouche et $\mathrm{al}^{5}$ and others working in this area are to be congratulated for providing relevant data.

However, care should be exercised when stating and using different test conditions for determining the humidification performance of HMEs: $V_{T}$ and frequency have independent effects on humidification performance that can be hidden if only the $\dot{V}_{\mathrm{E}}$ is stated.

The test methods specified in the current international standards to determine the humidification performance of HMEs and heated humidifiers are different and do not make comparisons between the different types of devices easy to make. It is hoped that a general test method can be developed that can be used for both types of devices (and for testing active HMEs) to make comparisons of performance easier. Consistent expired temperature and humidity settings are clearly important.

However, what is really needed now is a definitive study to determine the minimum (or preferably the optimum) level of humidification required for long-term artificial ventilation. Hopefully, we will not have to wait another 60 years.

Antony R Wilkes PhD Consultant, Medical Devices Hengoed

Wales, United Kingdom

\section{REFERENCES}

1. Lassen HCA. A preliminary report on the 1952 epidemic of poliomyelitis in Copenhagen with special reference to the treatment of acute respiratory insufficiency. Lancet 1953;261(6749):37-41.
2. Marshall J, Spalding JMK. Humidification in positive-pressure respiration for bulbospinal paralysis. Lancet 1953;262(6794):1022-1024.

3. Drägerwerk Lübeck. Deutsches Patentamt Patentschrift 1169615. Lübeck: Drägerwerk, August 27, 1954.

4. Kapadia F, Shelly MP, Anthony JM, Park GR. An active heat and moisture exchanger. Brit J Anaesth 1992;69(6):640-642.

5. Lellouche F, Qader S, Taillé S, Lyazidi A, Brochard L. Influence of ambient temperature and minute ventilation on passive and active heat and moisture exchangers. Respir Care 2014;59(5):637-643.

6. International Organization for Standardization. Anaesthetic and respiratory equipment-heat and moisture exchangers (HMEs) for humidifying respired gases in humans-part 1: HMEs for use with minimum tidal volumes of $250 \mathrm{ml}$ (ISO 9360-1:2000). Geneva: International Organization for Standardization; 2000.

7. International Organization for Standardization. Respiratory tract humidifiers for medical use-particular requirements for respiratory humidification systems (ISO 8185:2007). Geneva: International Organization for Standardization; 2007.

8. International Organization for Standardization. Anaesthetic and respiratory equipment-heat and moisture exchangers for use in humidifying respired gases in humans (ISO 9360:1992). Geneva: International Organization for Standardization; 1992.

9. Eckerbom B, Lindholm CE. Performance evaluation of six heat and moisture exchangers according to the Draft International Standard (ISO/DIS 9360). Acta Anaesthesiol Scand 1990;34(5):404-409.

10. Branson RD, Davis K Jr. Evaluation of 21 passive humidifiers according to the ISO 9360 standard: moisture output, dead space and flow resistance. Respir Care 1996;41(8):736-743.

11. Martin C, Papazian L, Perrin G, Bantz P, Gouin F. Performance evaluation of three vaporizing humidifiers and two heat and moisture exchangers in patients with minute ventilation $>10 \mathrm{~L} / \mathrm{min}$. Chest 1992;102(5):1347-1350.

12. Martin C, Thomachot L, Quinio B, Viviand X, Albanese J. Comparing two heat and moisture exchangers with one vaporizing humidifier in patients with minute ventilation greater than $10 \mathrm{~L} / \mathrm{min}$. Chest 1995;107(5):1411-1415.

13. ARDSNet (NIH NHLBI ARDS) Clinical Network. Mechanical ventilation protocol summary. http://www.ardsnet.org/system/files/ ventilator\%20protocol\%20card.pdf. Accessed January 24, 2014.

14. Chamney AR. Humidification requirements and techniques. Including a review of the performance of equipment in current use. Anaesthesia 1969;24(4):602-617.

15. Wilkes AR. Heat and moisture exchangers and breathing system filters: their use in anaesthesia and intensive care. Part 1-history, principles and efficiency. Anaesthesia 2011;66(1):31-39.

16. International Organization for Standardization. Humidifiers for medical use-safety requirements (ISO 8185:1988). Geneva: International Organization for Standardization; 1988.

17. Branson RD, Hurst JM. Laboratory evaluation of moisture output of seven airway heat and moisture exchangers. Respir Care 1987;32(9): 741-747.

18. Lellouche F, Taillé S, Maggiore SM, Qader S, L'Her E, Deye N, Brochard L. Influence of ambient air and ventilator output temperature on performances of heated-wire humidifiers. Am J Respir Crit Care Med 2004;170(10):1073-1079. 